\title{
The Effect of Two Training Methods: the Plyometric and the Strength Training, on the Economy to the Running and Explosiveness in Handball
}

\author{
Nebhan Hamid Ahmad \\ College of physical education, University of Anbar Iraq
}

\begin{abstract}
The aim of this study was to verify the impact of two specific training programs, strength training and plyometric and its impact in improving the economy to running and explosiveness in handball. In this regard, 12 adult subjects were invited to participate in the study. They were randomly divided into two groups of 6 players. The first group was stripped of plyometrics training; the second group underwent training on conventional fitness machines. Each group has been training 4 times a week for two hours per session for a period of 12 weeks. To determine the effect of each of the two training conditions, we measured the VO2 at $90 \%$ of the VMA, on a treadmill for 4 minutes and took the volume of oxygen consumed during the last minute as reference to the economy to the running. The explosiveness was measured by two vertical jump tests, SJ and CMJ using myotest. The variables presented are the jump height in cm, the velocity in $\mathrm{cm} / \mathrm{s}$, the power in $w / \mathrm{kg}$ and strength in $\mathrm{N} / \mathrm{kg}$. Also we measured movement speed by sprinting test on 10 and 20 meters. The quality of high-intensity intermittent running was measured by intermittent yoyo test 2 (YYIRT2). The results show a significant difference between the two groups (PRE vs. POST), and also between the two groups (POST Plyometrics vs POST strength training).
\end{abstract}

Keywords: plyometric training - Strength training - Explosiveness - Handball.

\section{Introduction}

\section{Plyometric Training}

Plyometric is a training method recommended for the improvement of the power in the triggers and running speed (Kotzamanidis, 2006). It leads to performance improvements particularly in activities requiring explosive muscular contractions (Malisoux et al, 2006). Besides its effect on explosiveness, plyometrics enhances performance in endurance runners, and, following an improvement of the economy in the running. Paavolainen et al, (1999) proposes that the running economy could be the best determinant of performance in endurance sports. A 5\% improvement in running economy can increase approximately the distance covered during a match of $1000 \mathrm{~m}$. (Hoff and Helgerud 2004). In the theory of training of strength, specific training to improve explosiveness is mentioned as "plyometric training". The method is called «Plyometric Method" (Stojanovic \& Kostić, 2002). The driving of plyometrics has been advocated as an appropriate approach to sport that requires explosiveness and improving the vertical jump (Eduardo saez et al, 2008). Rahimi et al, (2005) indicates that the drive for short-term plyometrics can improve vertical jump, muscle strength and anaerobic power. By cons, it recommends that its combination with a drive with load is even more advantageous. In volleyball players, plyometrics has led to increased explosive force of leg muscles and increased skills and perform better advanced jumps, depth jumps and triple jump permanent (Miller et al,, 2006).

In sum, plyometrics training can be advantageous to develop power and strength of the upper limbs (Jeffery et al, 2000). Plyometrics attributed to the execution of movements of the stretch-shortening cycle that involve intense eccentric contraction followed immediately, rapid and powerful concentric contraction (Goran, 2007). On the same voice, Ademola (2005) defines plyometric training as a method almost exclusively applied to the extensor muscles of the legs. It consists of a strong elongation of the extensor muscles active (eccentric contraction) smv1 immediately by a maximum concentric contraction. According to Eduardo Saez (2008) a "Term yard plyometrics training program with average frequency hopping and a drive means volume due to two days per week with 840 jumps the same effect with a program a higher drive frequency is 4 days per week with 1680 jumps, but with greater efficiency. In addition to its effectiveness in the development of explosive strength, plyometrics is used as injury prevention means. More specifically, the practical side, Rahimi et al, (2005) assume that the combination of different training methods promote the qualities of power and muscle strength. It shows in her study, done with college students that combine strength training with plyometrics program significantly increases the power of the hip and thigh, compared with a program or it uses two methods separately. These results indicate an improvement measured by the vertical jump.

\section{Strength Training}

If the muscle preparation has always seemed evident in the physical component to sports such as athletics, cycling and gymnastics for instance, it has not always been the case in disciplines such as team sports or sports snowshoes. Yet in those sports where technique and tactics remain the same basis of performance, he has become an illusion to achieve a high level of performance without considering physical preparation work within which strength training is of importance particular (Cometti, 2002 ; Le Gallais \& Millet, 2007). 


\section{International Journal of Science and Research (IJSR) \\ ISSN (Online): 2319-7064 \\ Index Copernicus Value (2013): 6.14 | Impact Factor (2015): 6.391}

In most team sports, the development of strength and explosiveness lies in the heart of the physical preparation. The work must be oriented not only propellants muscle groups but also on suppressive groups and stabilizers. Like most team sports, handball is constantly changing and requires, at all levels, preparation of increasingly sharp (Chelly et al, 2011; Povoas et al, 2012). If the players seem to be improving at the transition game, another prominent feature lays in the elevation of the players abilities to all positions to make ever more effective action in spaces and reduced playing time (Povoas et al, 2012; Martinet, 2007). Handball requires a very significant amount of physical commitment and it appears that the muscle work is actually an essential component of training. Several studies emphasize that to achieve the highest level, morphological and muscular qualities are essential (Gorostiaga, 2006; Granados, 2013).

\section{Methods}

\section{Subjects}

This research was conducted on 12 elderly handball players between 18 and 27 years from teams Alnnajaf, the Alkhalidun and Alshshatruth (Iraq), male, in good health and trained. The average age of gamers is 23 years \pm 2.7 , the size of the $1.88 \mathrm{~m} \pm 0.08$ and the average weight of all players is $75.3 \pm 7.4 \mathrm{~kg}$. All participants were informed about the experimental protocol and signed consent participation. This research was conducted on 12 elderly handball players between 18 and 27 years from Al Najaf teams, and the Khalidun Alshshatruth (Iraqi), male, in good health and trained. The average age of gamers is 23 years \pm 2.7, the size of the $1.88 \mathrm{~m} \pm 0.08$ and the average weight of all players is $75.3 \pm 7.4 \mathrm{~kg}$. All participants were informed about the experimental protocol and signed consent participation.
Table 1: Physical characteristics of participants (mean and $\mathrm{Sd})$.

\begin{tabular}{|c|c|c|}
\hline \multicolumn{2}{|c|}{ Physical characteristics of participants (mean and Sd). } \\
\hline & Strength Training & Plyometrics \\
\hline Age & $20.2 \pm 2.4$ & $21.3 \pm 2.9$ \\
\hline Saizes (m) & $1.89 \pm 0.1$ & $1.90 \pm 0.06$ \\
\hline Weight (kg) & $76.2 \pm 8.4$ & $72.04 \pm 10.1$ \\
\hline VMA & $16.5 \pm 0.6$ & $17.3 \pm 1.0$ \\
\hline Vo2 max & $57.8 \pm 2.0$ & $60.4 \pm 3.4$ \\
\hline
\end{tabular}

\section{Experimental Protocol}

Our study population was randomly distributed into two groups of 6 players. One group followed a working plyometrics and the second group was subjected to conventional weight training. Each group has trained four times a week for two hours per session for a period of 12 weeks. To determine the effect of each of the two training conditions, we measured the VO2 $90 \%$ of the VMA, on a treadmill for 4 minutes and took the volume of oxygen consumed during the last minute as reference the economy in the running. The explosion was measured by two vertical expansion tests, the Jump Squat force $(\mathrm{N} / \mathrm{kg}$ ) and the Counter Movement Jump Force ( $\mathrm{N} / \mathrm{kg}$ ). We measured the absolute oxygen consumption ( $\mathrm{ml} / \mathrm{min}$ ) and the relative oxygen consumption ( $\mathrm{ml} / \mathrm{min}$ ). Also, we measured the speed of movement in the sprint test on 10 and 20 meters per second. The quality of high-intensity intermittent running was measured by intermittent yoyo test 2 (YYIRT2). For the evaluation of the data, a model group (control vs. experimental) by testing with repeated measurements on the test, that is to say, a factor model with smaller blocks (Kirk, 1992) was applied to raise the differences significant between the control group and the experimental group.

\section{Results}

All of our results are shown in Table 2.

\begin{tabular}{|c|c|c|c|c|c|c|}
\hline \multirow[b]{2}{*}{ Variables } & \multicolumn{2}{|c|}{ Plyometric } & \multirow{2}{*}{$\begin{array}{c}\text { Gains } \\
\text { Abs }\end{array}$} & \multicolumn{2}{|c|}{ Strength Training } & \multirow{2}{*}{$\frac{\text { Gains }}{\text { Abs }}$} \\
\hline & Pre-test & Post-test & & Pre-test & Post-test & \\
\hline SJfor $(\mathrm{N} / \mathrm{kg})$ & $24.5 \pm 2.21$ & $27.2 \pm 3.49^{*}$ & 2,7 & $25.6 \pm 2.54$ & $27.7 \pm 2.38^{*}$ & 2,1 \\
\hline CMJfor (N/kg) & $24.2 \pm 0.08$ & $28.9 \pm 7.53^{*}$ & 4,7 & $23.6 \pm 1.18$ & $26.8 \pm 2.20^{*}$ & 3,2 \\
\hline $\mathrm{Vo} 2 \mathrm{abl}(\mathrm{ml} / \mathrm{min})$ & $2949.3 \pm 11,84$ & $3904.2 \pm 669.39^{*}$ & 954,9 & $2750.8 \pm 479.99$ & $3678.6 \pm 216.09^{*}$ & 927,8 \\
\hline $\mathrm{Vo} 2 \mathrm{rl}(\mathrm{ml} / \mathrm{min})$ & $38.8 \pm 11.843$ & $51.7 \pm 2.95^{*}$ & 12,9 & $36.3 \pm 6.788$ & $48.0 \pm 7.07^{*}$ & 11,7 \\
\hline
\end{tabular}

Mean \pm SD; *Significant Differences Pre vs Post Test; Significant Differences Plyometric vs Strength Training; SJFor: Squat Jump Force; CMJFor: Counter Movement Jump Force; $\mathrm{VO}_{2}$ Abs: Absolute Oxygen Consumption; $\mathrm{VO}_{2}$ $\mathrm{Rl}$ : Relative Oxygen Consumption.

Our results show that 12 plyometrics workouts and strength training lead to a significant improvement of the variables tested in handball. This improvement both within and between groups by comparing the pre and post test. As indicated in the table above for the group if exercising plyometrics training, a significant increase of the measured variables, SJFor (24.5 in pre test vs 27.2 in post test), CMJFor (24.2 in pre test vs 28.9 in post test), VO2 Abs (2949 $\mathrm{ml} / \mathrm{min}$ in pre-test vs $3904 \mathrm{ml} / \mathrm{min}$ in post test),
VO2 Rl (38.8 ml / min in pre-test vs. $51.7 \mathrm{ml} / \mathrm{min}$ in post test).

Similarly comparing pre and post tests, we noticed beneficial effect of weight training in handball examined. Thus we find (25.6 vs 27.7 for SJFor test), (23.6 vs 26.8 CMJFor) (2750.8 vs $3678.6 \mathrm{VO}_{2} \mathrm{Abl}$ ) and (36.3 vs 48.0 $\left.\mathrm{VO}_{2} \mathrm{Rl}\right)$.

Our statistical analysis has shown by comparing the results of the groups improved parameters tested was for the plyometrics group (CMJFor: 28.9 vs 26.8; $\mathrm{VO}_{2} \mathrm{Abs:} 3904.2$ vs 3678.6; VO2 Rl: 51,7 vs 38,0) with one variable that had a slight favour of the group performing a strength training program (SJFor: 27.7 vs 27.2). 


\section{International Journal of Science and Research (IJSR) \\ ISSN (Online): 2319-7064 \\ Index Copernicus Value (2013): 6.14 | Impact Factor (2015): 6.391}

\section{Discussions}

In a discipline such as handball, muscle development is an essential component of training because it allows running faster, jump higher, throw harder and dominating his opponent in duels. When one has only three training sessions per week, it is rare Coach sacrifice time for muscle development. Yet it appears that a relatively labour short, limited effort series and very constraining, has some efficacy (Carpinelli \& Winett, 2004).

In our study and through the application of two training programs plyometric and strength training in handball, it was noted that both methods have a marked improvement in variables tested by comparing the pre and post tests. This shows us the importance of these two training methods in the development of physical qualities in handball which confirms the work of (Cometti, 2002; Le Gallais \& Millet, 2007; Chelly et al, 2011).

Furthermore this study has allowed us to see the effectiveness of plyometric training which proved a great improvement of the tested variables such as (SJFor, CMSJFor, $\mathrm{VO}_{2}$ Abs and $\mathrm{VO}_{2} \mathrm{Rl}$ ) that agree with the studies (Rahimi et al, 2005 ; Hoff and Helgerud 2004; Ademola, 2005).

Also this importance of plyometric training is increasingly clear when it is compared to strength training. This latter is less important although it has proven a bitter improvement after a period of 12 training sessions. Therefore, we can say that the plyometric training method is better than strength, and this is going in the same direction of the work of (Chelly et al, 2011; Povoas et al, 2012 ; Gorostiaga, 2006; Granados, 2013; Goran, 2007; Stojanovic, 2002; saez et al, 2008).

\section{Conclusion}

We can conclude that the plyometric method has a great importance for the development of physical qualities of handballers. This is confirmed by the marked improvement of the parameters tested in this study.

\section{References}

[1] Ademola, O. Abass. (2005). Correlational effects of plyometric training on leg muscle strength, endurance and power characteristics of nigerian university undergraduates. International Journal of African \& African American Studies Vol. IV, No. 1, 42-52 pp.

[2] Carpinelli, RNO. R., Winett, R.A.(2004). A critical analysis of the ACSM position stand on resistance training: insufficient évidence to support recommended training protocols. J. Exerc Physio;7:1-60.

[3] Chelly, M.S., Hermassi, S., Aouadi, R., Khalifa, R., Van den Tillaar, R., Chamari, K., et al. (2011). Match analysis of élite adolescent team handball players. J Strength Cond Res; 25:2410-7.

[4] Cometti, G.(2002). La préparation physique en football. Paris: Chiron.
[5] Goran, M. (2007). Does plyometric training improve vertical jump height? A meta-analytical review; British Journal of Sports Medicine; 41, 349-355.

[6] Gorostiaga, E.M., Granados, C., Ibanez, J., GonzalezBadillo, J.J., Izquierdo M.(2006). Effects of an entire season on physical fitness changes in élite male handball players. Med Sci Sports Ex;38:357-66.

[7] Granados, C., Izquierdo, M., Ibanez, J., Ruesta, M., Gorostiaga, E.M. (2013). Are there any différences in physical fitness and throwing velocity between national and international élite female handball players? J Strength Cond Res 2013;27:723-32.

[8] Hoff, J. and Helgerud, J. (2004). "Endurance and strength training for soccer players: physiological considerations." Sports Med 34(3): 165-180.

[9] Jeffery, F., Vossen., John, F., Kramer, D., Burke, G. and Deborahp. V. (2000). Comparison of Dynamic Push-Up Training and Plyometric Push-Up Training on UpperBody Power and Strength. J Strength Cond Res. 2000, 14(3), 248-253.

[10] Kotzamanidis, C. (2006). Effect of plyometric training on running performance and vertical jumping in prepubertal boys.Journal of Strength and Conditioning Research 20, 441-445.

[11]Le Gallais, D \& Millet, G. (2007). La préparation physique optimisation et limites de la performance sportive. Issy-les-Moulineaux: Elsevier - Masson.

[12] Malisoux, L., Francaux, M., Nielens, H., Theisen,D.(2006). Stretch-shortening cycle exercises: an effective training paradigm to enhance power output of human single muscle fibers, J Appl Physiol, 100, 3, p. 771-9.

[13] Miller, M.G., Herniman, J.J., Richard, M.D., Cheatham, C.C., Michael, T.J.(2006). The effects of a 6-week plyometric training program on agility. J Sports Sci Med. 5:459-465.

[14] Paavolainen, L., Häkkinen, K., Hämäläinen I., Nummela, A. \& Rusko, H. (1999) Explosive-strength taining improves 5-km running time by improving running economy and muscle power. J. Appl. Physiol. 86(5): 1527- 1533.

[15] Povoas, S.C., Seabra, A.F., Ascensao, M., Magalhaes, J., Soares, J.M., Rebelo, A.N. (2012). Physical and physiological demands of élite team handball. $\mathrm{J}$ Strength Cond Res; 26:3365-75. Martinet, J.P. (2007). Handball. Paris: Vigot.

[16] Rahimi; R., Behpur, N. (2005). The effects of plyometric, weight and plyometric-weight training on anaerobic power and muscular strength. Physical Education and Sports. v. 3, p. 81-91.

[17] Saez De Villarreal, E., Gonzalez-Badillo, J.J., \& Izquierdo, M. (2008). Low and moderate plyometric training frequency produce greater jumping and sprinting gains compared with high frequency. Journal of Strength and Conditioning Research, 22, 715-725.

[18] Stojanović, T., \& Kostić, R. (2002). The effects of the plyometric sport training model on the development of the vertical jump of volleyball players. Facta Univ Phys Educ Sport, 1(9), 11-25. 